BBA 57840

\title{
EVIDENCE FOR A REGULATORY ROLE OF CTP : CHOLINE PHOSPHATE CYTIDYLYLTRANSFERASE IN THE SYNTHESIS OF PHOSPHATIDYLCHOLINE IN FETAL LUNG FOLLOWING PREMATURE BIRTH
}

\author{
PAUL A. WEINHOLD, DOUGLAS A. FELDMAN, MARY M. QUADE, JOSEPH C. MILLER and ROBERT L. BROOKS
}

Veterans Administration Medical Center and Department of Biological Chemistry, University of Michigan, Ann Arbor, MI 48105 (U.S.A.)

(Received January 28th, 1981)

Key words: CTP : cholinephosphate cytidylyltransferase; Development; Phosphatidylcholine; Pulmonary surfactant; (Fetal rat lung)

The sequence of reactions which function to incorporate choline into phosphatidylcholine was investigated in lung from fetuses following premature delivery. The rate of $\left[\right.$ methyl $\left.{ }^{14} \mathrm{C}\right]$ choline incorporation by rat lung slices into phosphatidylcholine increases following premature delivery at both 20 and 21 days gestation. The increase in choline incorporation is primarily due to an increased specific activity of phosphorylcholine resulting from a decreased pool size of phosphorylcholine. The decrease in the concentration of phosphorylcholine following premature delivery is apparently caused by an increased activity of cytidylyltransferase which leads to an increase in the conversion of phosphorylcholine to phosphatidylcholine. The total activity of choline kinase, cytidylyltransferase, cholinephosphotransferase and phosphatidate phosphohydrolase did not change significantly. However, the cytidylyltransferase activity in the microsome fraction increased following premature delivery at 20 and 21 days gestation. The amount of cytidylyltransferase in the $\mathrm{H}$ form in the cytosol fraction increased following premature delivery at 21 days gestation but not at 20 days gestation. The results are interpreted to indicate that the active form of cytidylyltransferase in lung cells is the membrane-bound enzyme and this form increases following birth resulting in an increased synthesis of phosphatidylcholine.

\section{Introduction}

We previously reported that approximately $50-$ $60 \%$ of fetal rats delivered 2 days prematurely survive when placed in an incubator [1]. Lung slices from the fetuses surviving $3 \mathrm{~h}$ incorporated significantly more $\left[\right.$ methyl $\left.{ }^{14} \mathrm{C}\right]$ choline into phosphatidylcholine than slices from lungs removed from fetuses immediately after delivery. The increase appeared to be specific to the choline pathway since the incorporation of other lipid precursors did not increase. The extent of the increased $\left[\right.$ methyl $\left.{ }^{14} \mathrm{C}\right]$ choline incorporation by lung slices after $3 \mathrm{~h}$ of survival was

Abbreviation: Hepes, $N-2$ hydroxyethylpiperazine- $N^{\prime}-2-$ ethanesulfonic acid. similar to that obtained either in utero after an additional $24-30 \mathrm{~h}$ of gestation or at 20 days gestation after injection of dexamethasone to mothers at 17 and 18 day gestation. Thus, the metabolic processes resulting in the apparent rapid increase in the activity of the biosynthetic pathway for phosphatidylcholine synthesis following premature birth may be similar to those occurring more slowly during in utero development and after accelerated development produced by dexamethasone [2,3].

The purpose of this report is to present the results of more detailed studies on the reactions in the pathway for the incorporation of choline into phosphatidylcholine. The intact pathway for choline incorporation was studied in more detail by comparing the ability of lung slices to incorporate $\left[\right.$ methyl $\left.{ }^{14} \mathrm{C}\right]$ choline into phosphorylcholine, CDPcholine and phosphati- 
dylcholine. We also measured the activity of choline kinase (EC 2.7.1.32) CTP : cholinephosphate cytidylyltransferase (EC 2.7.7.15), CDPcholine : diacylglycerol cholinephosphotransferase (EC 2.7.8.2), and phosphatidate phosphohydrolase (EC 3.1.3.4) in lungs removed from fetuses immediately after premature delivery and from fetuses surviving $3 \mathrm{~h}$. The subcellular distribution of cytidylyltransferase and the distribution of cytidylyltransferase activity in cytosol between the $\mathrm{L}$ form and $\mathrm{H}$ form of the enzyme was also determined. The combined results from these experiments indicate that changes in cytidylyltrans. ferase activity may be controlling factor in the increased ability of lung from premature fetuses to incorporate $\left[\right.$ methyl $\left.-{ }^{14} \mathrm{C}\right]$ choline into phosphatidylcholine. Furthermore, the increased activity appears to be related to an increase in cytidylyltransferase activity in the microsome fraction.

\section{Materials and Methods}

Pregnant rats (sperm positive) were obtained from Holtzman Co, Madison WI. The premature delivery and care of the newborn were described previously [1]. The methods for the preparation of lung slices, for slice incubations, for lipid extractions and for lipid analysis were described in detail previously [1]. Phosphatidylglycerol (prepared from egg phosphatidylcholine), inorganic pyrophosphatase (Type III baker's yeast) and alkaline phosphatase (Type III, calf intestine) were obtained from Sigma Chemical Co.

\section{Enzyme activities}

Choline kinase activity was determined with a reaction mixture that contained $12 \mathrm{mM}$ ATP, $13 \mathrm{mM}$ $\mathrm{Mg}^{2+}, 100 \mathrm{mM}$ Tris buffer, $\mathrm{pH} 8.5,1 \mathrm{mM}$ [methyl${ }^{14} \mathrm{C}$ ] choline $(4400 \mathrm{dpm} / \mathrm{nmol})$ and $100000 \times g$ supernatant in a total volume of $0.1 \mathrm{ml}$. The reaction was incubated at $37^{\circ} \mathrm{C}$, stopped by boiling for $2 \mathrm{~min}$, and the phosphorylcholine isolated as described previously [4]. A $20 \%$ lung homogenate was prepared in $0.25 \mathrm{M}$ sucrose $/ 1.0 \mathrm{mM}$ EDTA/10 mM Hepes $(\mathrm{pH}$ $7.4) / 2.0 \mathrm{mM}$ dithiothreitol. The reaction rate was directly proportional to the amount of $100000 \times g$ supernatant up to $25 \mu \mathrm{l}$ and with time for $20 \mathrm{~min}$. The apparent $K_{\mathrm{m}}$ for choline was estimated to be 0.1 $\mathrm{mM}$ and the apparent $K_{\mathrm{m}}$ for ATP was estimated to be $2.0 \mathrm{mM}$.
Cholinephosphotransferase activity was measured in the total particulate fraction. This fraction consisted of particulate material that sedimented between $1000 \times g \times 10 \mathrm{~min}$ and $100000 \times g \times 60 \mathrm{~min}$. Tissue was homogenized in $0.25 \mathrm{M}$ sucrose containing $5 \mathrm{mM}$ EDTA, $28 \mathrm{mM} \mathrm{Mg}^{2+}$ and $78 \mathrm{mM}$ Tris buffer, $\mathrm{pH} 8.2$. The sedimented particulate was suspended in homogenizing buffer and stored at $-20^{\circ} \mathrm{C}$ until used for assays. The particulate was stored no longer than 2 weeks before enzyme activity was measured. The activity did not change over the 2 weeks of storage. Just prior to use for enzyme assays a portion of the particulate was diluted with assay buffer mixture to a protein concentration of $1 \mathrm{mg} / \mathrm{ml}$. The assay mixture contained $5 \mathrm{mM}$ EDTA, $10 \mathrm{mM}$ dithiothreitol, 25 $\mathrm{mM} \mathrm{MgCl} 2,70 \mathrm{mM}$ Tris, $\mathrm{pH} 8.2$ (these four ingredients were added together and are referred to above as assay buffer mixture), $10 \mathrm{mM}$ CDP$\left[{ }^{14} \mathrm{C}\right]$ choline $(600-700 \mathrm{dpm} / \mathrm{nmol}, 5 \mathrm{mM}$ 1,2-dioleoylglycerol, $1 \mathrm{mg} / \mathrm{ml}$ Tween 20 , and particulate (up to $50 \mu \mathrm{g}$ protein) in a final volume of $0.5 \mathrm{ml}$. The 1,2-dioleoylglycerol/Tween 20 mixture was prepared by sonication in assay buffer mixture for $10 \mathrm{~min}$ in a Heat Systems Sonicator. The ratio of diacylglycerol to Tween 20 was kept constant at $0.2 \mathrm{mg}$ of Tween 20 for each $\mu \mathrm{mol}$ of diacylglycerol. This ratio resulted in a substrate mixture which gave maximal enzyme activity. Either an increase or decrease in the ratio caused a decrease in enzyme activity. The reac. tion mixture was incubated for $20 \mathrm{~min}$ at $30^{\circ} \mathrm{C}$ and was stopped by the addition of $3.0 \mathrm{ml}$ of $2: 1$ methanol/chloroform. The extraction of phosphatidylcholine was completed by adding an additional 1.0 $\mathrm{ml}$ chloroform and $1.3 \mathrm{ml}$ of water. The resulting two phases were separated by brief centrifugation and the lower chloroform phase washed twice with $2 \mathrm{ml}$ of $1: 1$ methanol/water. The chloroform extract was transferred to a scintillation vial, the chloroform was evaporated, $10 \mathrm{ml}$ of scintillation fluid was added and the radioactivity was determined. The reaction rate was constant for $60 \mathrm{~min}$ and was proportional to the amount of particulate to at least $100 \mu \mathrm{g}$ of protein.

Phosphatidate phosphohydrolase was assayed by a slight modification of the method described previously [5]. The concentration of 1,2-dioleoylglycerol 3-phosphate was increased to $2.0 \mathrm{mM}$. Total particulate fraction was used as the enzyme source. The particulate was prepared exactly as described for 
cholinephosphotransferase. A portion of this particulate fraction was diluted to $1 \mathrm{mg}$ protein/mg with 100 $\mathrm{mM}$ Tris-maleate buffer, $\mathrm{pH} 6.4$, just prior to performing the assay.

Cytidylyltransferase was assayed in the forward direction as described previously [6]. The determination of size distribution of cytidylyltransferase in cytosol was performed by agarose gel filtration by methods previously described [6].

Determination of the incorporation by lung slices of [methyl. ${ }^{14} \mathrm{C}$ ] choline into choline, phosphorylcholine, CDPcholine and phosphatidylcholine

Tissue slices were transferred from the incubation flasks to centrifuge tubes and rinsed twice with cold saline. The slices were extracted with $2: 1$ chloroform/methanol. The chloroform/methanol was separated into two phases by the addition of water and the upper methanol/water phase removed. The tissue residue was extracted an additional three times with $20 \%$ ethanol and the ethanol extracts were added to the methanol/water extracts. These combined extracts contained the water-soluble components of the tissue. The combined extracts were evaporated to dryness in a vacuum rotary evaporator. The residue was dissolved in water. Choline, phosphorylcholine and CDPcholine were separated by thin-1ayer chromatography on silica gel 60 plates in the solvent system $0.15 \mathrm{M} \mathrm{NaCl} /$ methanol/conc. $\mathrm{NH}_{4} \mathrm{OH},(50: 50: 5)$. The radioactive choline, phosphorylcholine and CDPcholine were detected by autoradiography using $\mathrm{X}$-ray film. The radioactive areas on the chromatogram were scraped directly into scintillation vials that contained $10 \mathrm{ml}$ of PCS scintillation fluid. The percentage distribution was calculated and used to calculate the total amount of radioactivity in each compound in the total extract.

The silica scrapings that contained phosphorylcholine were recovered from the scintillation vials and rinsed once with toluene to remove any remaining scintillation fluid. Cholinephosphate was extracted from the silica gel scrapings by sequential extractions with ethanol, ethanol/water $1: 1$ and water; This extraction method was found to give $90-100 \%$ recovery of radioactivity. The combined extracts were evaporated to dryness in a vacuum evaporator. The residue was dissolved in several aliquots of water and filtered through glass wool to remove precipi- tated silica gel and was stored at $-40^{\circ} \mathrm{C}$ until used for the measurement of phosphorylcholine content.

Phosphorylcholine was determined by a modification of the method described by Choy et al. [7]. Samples and phosphorylcholine standards were incubated at $37^{\circ} \mathrm{C}$ for $60 \mathrm{~min}$ in a mixture of $0.1 \mathrm{M}$ Tris buffer, $\mathrm{pH} 7.4,0.26 \mathrm{mM}$ phosphatidylglycerol, 12 $\mathrm{mM} \mathrm{Mg}^{2+}, 0.01$ units of inorganic pyrophosphatase, $1.0 \mathrm{mM}\left[{ }^{3} \mathrm{H}\right] \mathrm{CTP}(5 \mu \mathrm{Ci} / \mu \mathrm{mol})$ and 2 units of cytidylyltransferase (see below for preparation) in a final volume of $0.1 \mathrm{ml}$. The reaction was stopped by placing the tubes in boiling water for $2 \mathrm{~min}$, followed by cooling on ice. This incubation converted the phosphorylcholine to CDPcholine. The excess $\left[{ }^{3} \mathrm{H}\right]$ CTP was hydrolyzed with alkaline phosphatase by adding to the cooled reaction mixture $45 \mu \mathrm{mol}$ Trisglycine buffer, $\mathrm{pH} 10.5,0.22 \mu \mathrm{mol}$ of CDPcholine and 20 units of alkaline phosphatase (1 000 units $/ \mathrm{mg}$ protein). The reaction was allowed to proceed at $37^{\circ} \mathrm{C}$ for $1 \mathrm{~h}$ and was stopped by placing in boiling water for $2 \mathrm{~min}$. An aliquot of this solution was spotted on Whatman $3 \mathrm{MM}$ chromatography paper. The chromatogram was developed in the solvent system ethanol/1 $\mathrm{M}$ ammonium acctate, $\mathrm{pH} 7.1,(7$ : 3 ). The area of the chromatogram corresponding to CDPcholine was cut out and placed in scintillation vials which contained $1.5 \mathrm{ml}$ of $0.1 \mathrm{M} \mathrm{HCl}$. PCS scintillation fluid was added after $30 \mathrm{~min}$ and the radioactivity determined in a Beckman Scintillation spectrometer set for double-label determination of ${ }^{3} \mathrm{H}$ and ${ }^{14} \mathrm{C}$. The determination of ${ }^{3} \mathrm{H}$ dpm in the CDPcholine was used to calculate the amount of phosphorylcholine. Since the CDPcholine was synthesized from phosphorylcholine containing [methyl${ }^{14} \mathrm{Cl}$, the ${ }^{14} \mathrm{C} \mathrm{dpm}$ in the CDPcholine was used to calculate the original specific activity of the phosphorylcholine. The content of phosphorylcholine in the original tissue extract was subsequently calculated by dividing the total ${ }^{14} \mathrm{C} \mathrm{dpm}$ of phophorylcholine by the calculated specific activity $(\mathrm{dpm} / \mathrm{nmol})$. The standard curve for phosphorylcholine in the above assay was linear from 1 to $15 \mathrm{nmol}$ per assay. The silica gel thin-layer chromatography system used to initially isolate phosphorylcholine does not separate phosphorylcholine from phosphorylethanolamine. Thus, any phosphorylethanolamine present in the extract would be present in the $\left[{ }^{3} \mathrm{H}\right] \mathrm{CTP}$-cytidylyltransferase reaction. However, the paper chromatog- 
raphy system clearly separates CDPcholine from CDPethanolamine and eliminates any possible contribution of phosphorylethanolamine to the phosphorylcholine values.

Cytidylyltransferase was prepared from rat liver cytosol. The tissue was homogenized in $4 \mathrm{vol}$. (w/v) of $50 \mathrm{mM}$ Tris $-\mathrm{HCl}(\mathrm{pH} 7.4)$ containing $150 \mathrm{mM}$ $\mathrm{NaCl}$. After centrifugation at $100000 \times \mathrm{g}$ for $60 \mathrm{~min}$, the supernatant was applied to a Biogel 5.0 agarose column $(2.8 \times 90 \mathrm{~cm})$ equilibrated with the Tris $/ \mathrm{NaCl}$ buffer. Cytidylyltransferase enzyme activity that eluted slightly ahead of the elution volume of hemoglobin was collected and concentrated by ultrafiltration (Amicon YM-10 filter). The enzyme preparations normally exhibited an activity of $18-25 \mathrm{nmol} / \mathrm{min}$ per $\mathrm{ml}$ at a specific activity of $3 \mathrm{nmol} / \mathrm{min}$ per $\mathrm{mg}$ protein. The preparations were stored at $4^{\circ} \mathrm{C}$ for up to 2 weeks.
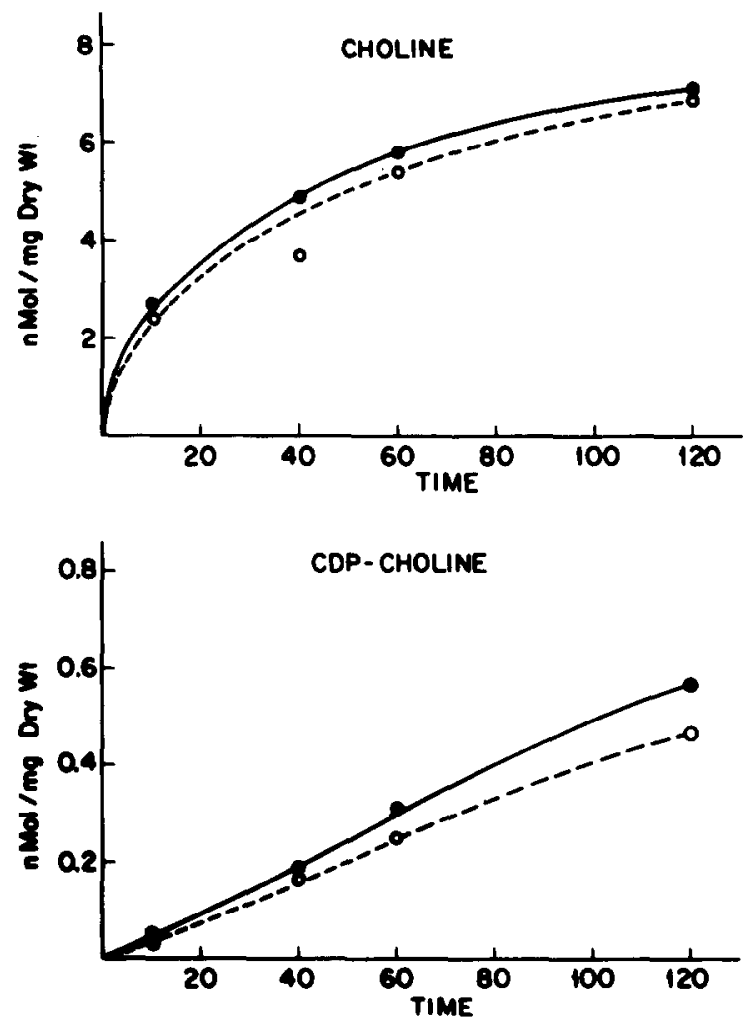

Subcellular fractionation for cytidylyltransferase activity

Lung was homogenized in $4 \mathrm{vol}$. (w/v) of $50 \mathrm{mM}$ Tris- $\mathrm{HCl}(\mathrm{pH} 7.4$ ) containing $150 \mathrm{mM} \mathrm{NaCl}$. The homogenate was centrifuged at $1000 \times g$ for $5 \mathrm{~min}$ and the pellet discarded. The $1000 \times g$ supernatant was centrifuged at $20000 \times g$ for $30 \mathrm{~min}$. The resulting supernatant contained about $90 \%$ of the cytidylyltransferase activity in the original homogenate. The $20000 \times g$ supernatant was centrifuged at $250000 \times$ $g$ for $60 \mathrm{~min}$ to yield a pellet (microsomes) and a supernatant (cytosol).

\section{Other methods}

Lung dry weight was obtained by drying preweighed pieces of fresh lung at $100^{\circ} \mathrm{C}$ for $24 \mathrm{~h}$. DNA was measured as described by Burton [8]. Protein was determined by the method of Lowry et al. [9] with bovine serum albumin as standard.
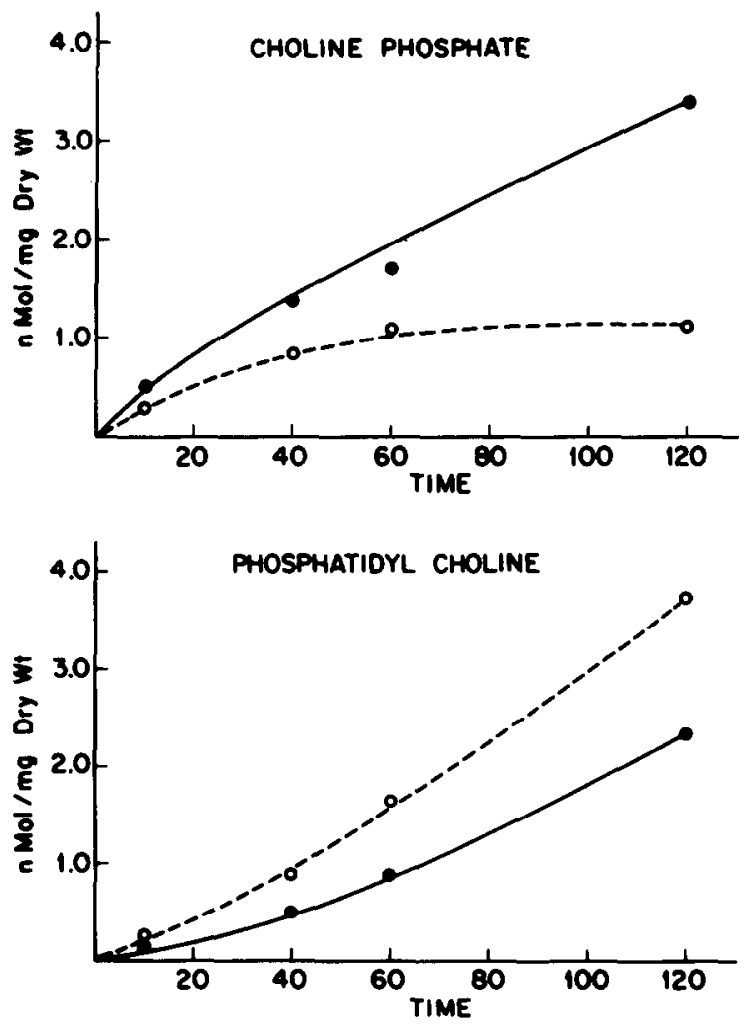

Fig. 1. The rate of incorporation of $\left[\right.$ methyl $\left.-{ }^{14} \mathrm{C}\right]$ choline by lung slices at 20 days gestation. Each point is the average of duplicate incubations of $180-200 \mathrm{mg}$ of wet tissue per incubation. The nmol incorporated is calculated from the total radioactivity in each isolated compound divided by the specific activity of the [methyl $\left.{ }^{14} \mathrm{C}\right]$ choline added to the incubation medium. $\bullet$, at birth; $\circ, 3 \mathrm{~h}$ after birth. 


\section{Results}

[methyl $-{ }^{14} \mathrm{C}$ ]Choline incorporation into phosphorylcholine, CDPcholine and phosphatidylcholine by lung slices

Pregnant rats were delivered by cesarean section at either 20 day or 21 day gestation. Approximately half of the litter was killed immediately and the lungs removed for slice experiments. The remaining fetuses were placed in an incubator for $3 \mathrm{~h}$. After $3 \mathrm{~h}$ in the incubator the surviving fetuses were killed and their lungs removed for slice experiments. At 20 day gestation the rate of incorporation of $\left[\right.$ methyl $\left.-{ }^{14} \mathrm{C}\right] \mathrm{cho}$ line into phosphatidylcholine was approximately 2 -fold higher at $3 \mathrm{~h}$ than immediately after delivery (Fig. 1). The increased incorporation of [methyl${ }^{14} \mathrm{C}$ ]choline into phosphatidylcholine was accompanied by a decrease in the rate of incorporation into phosphorylcholine. The rates of $\left[\right.$ methyl- $\left.{ }^{14} \mathrm{C}\right] \mathrm{cho}$ line incorporation into CDPcholine and tissue

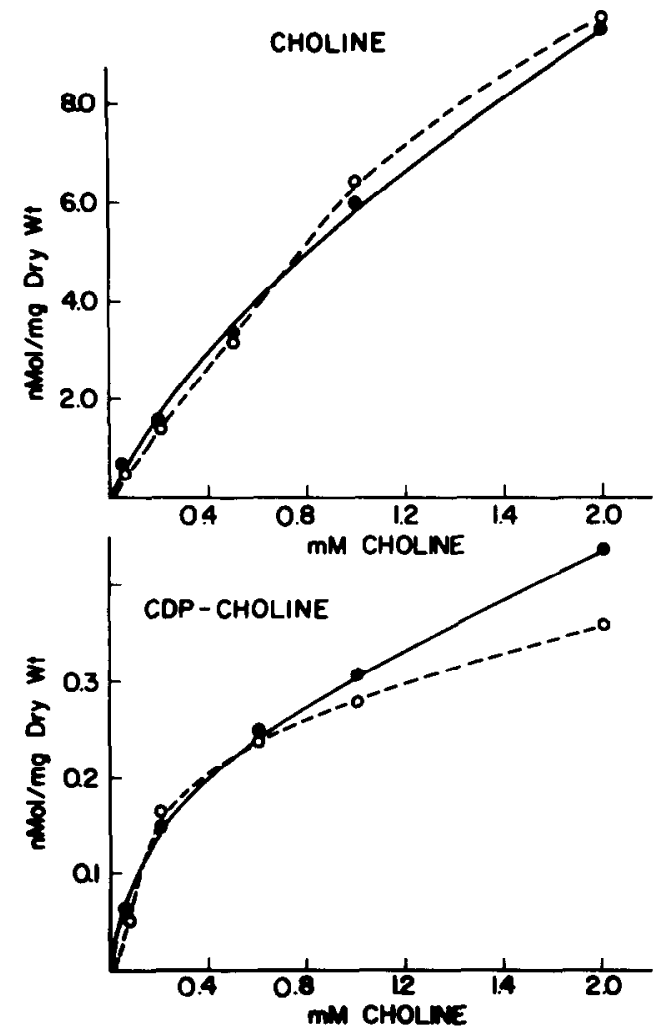

$\left[\right.$ methyl $\left.-{ }^{14} \mathrm{C}\right]$ choline did not change significantly.

The amount of $\left[\right.$ methyl $\left.-{ }^{14} \mathrm{C}\right]$ choline incorporated into phosphatidylcholine after $1 \mathrm{~h}$ of incubation increased with increasing concentrations of [methyl${ }^{14} \mathrm{C}$ choline, producing an apparent hyperbolic saturation curve (Fig. 2). The concentration of added $\left[\right.$ methyl $\left.{ }^{14} \mathrm{C}\right]$ choline required to produce an apparent half maximal incorporation into phosphatidylcholine was $0.17 \mathrm{mM}$ for lung slices from both newborn and 3-h-surviving fetuses. However, the maximal amount of incorporation into phosphatidylcholine at near saturating concentration of choline was again about 2 -fold higher in slices from fetuses surviving for $3 \mathrm{~h}$. The incorporation of $\left[\right.$ methyl $\left.-{ }^{14} \mathrm{C}\right]$ choline into phosphorylcholine also increased hyperbolically, but the maximal amount of incorporation into phosphorylcholine at near saturating concentrations of choline was significantly lower in lung slices from fetuses surviving $3 \mathrm{~h}$.

The relative rate of entry of choline into the path-
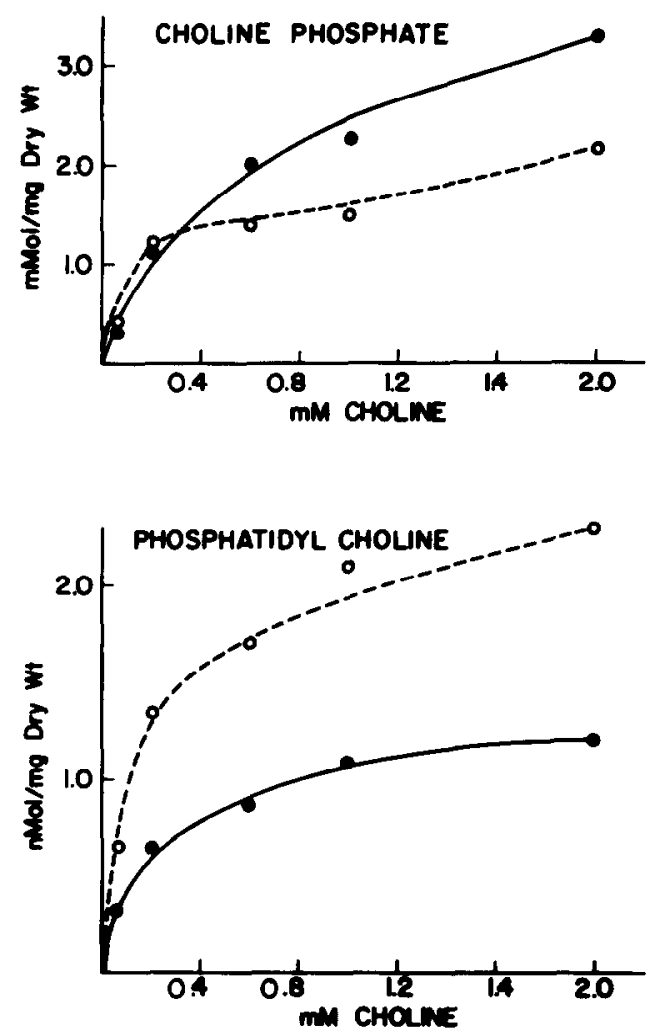

Fig. 2. The incorporation of $\left[\right.$ methyl. $\left.{ }^{14} \mathrm{C}\right]$ choline at varying concentrations of choline. Duplicate incubations were performed for $1 \mathrm{~h}$ at each choline concentration. $\bullet$, at birth; $0,3 \mathrm{~h}$ after birth. 
way through the choline kinase reaction was estimated by assuming that the sum of radioactivity in phosphorycholine, CDPcholine and phosphatidylcholine was a measurement of the total amount of cho. line phosphorylated during the period of incubation. This rate of entry did not differ between lung slices from fetal rats immediately after delivery and from. animals surviving $3 \mathrm{~h}$ (Fig. 3). The amount of [methyl $-{ }^{14} \mathrm{C}$ ]choline entering the pathway with different choline concentration in the incubation medium also did not differ between the two groups of fetuses (Fig. 4). Thus, the differences in the incorporation of $\left[\right.$ methyl $\left.{ }^{14} \mathrm{C}\right]$ choline into phosphorylcholine and phosphatidylcholine was not due to changes in the amount of radioactive choline entering the pathway but rather to a shift in the distribution of the radioactive choline in subsequent metabolites in the pathway.

Similar experiments were performed at 21 days gestation. The rate of $\left[\right.$ methy $\left.l^{14} \mathrm{C}\right]$ choline incorporation into phosphatidylcholine increased from 1.8 $\mathrm{nmol} / \mathrm{h}$ per $\mathrm{mg}$ dry weight immediately after birth to $2.3 \mathrm{nmol} / \mathrm{h}$ per $\mathrm{mg}$ dry weight after $3 \mathrm{~h}$ of survival. A decrease in the incorporation of $\left[\right.$ methyl $\left.-{ }^{14} \mathrm{C}\right]$ choline

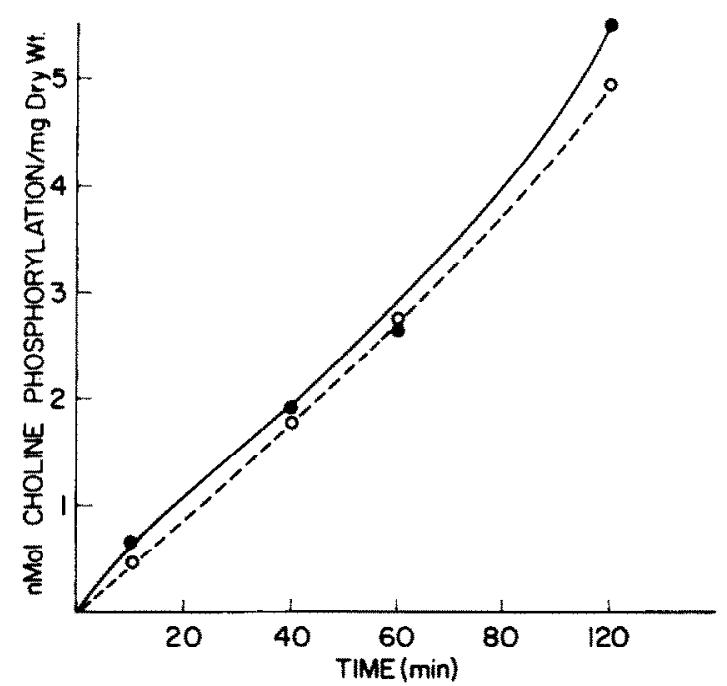

Fig. 3. The rate of choline phosphorylation by lung slices from 20-day gestation fetuses. Each point is the average of duplicate incubation. The values are calculated by adding the $\mathrm{cpm}$ in phosphorylcholine, CDPcholine and phosphatidylcholine. $\bullet$, lung slices from fetuses immediately after delivery; 0 , lung slices from fetuses that survived $3 \mathrm{~h}$.

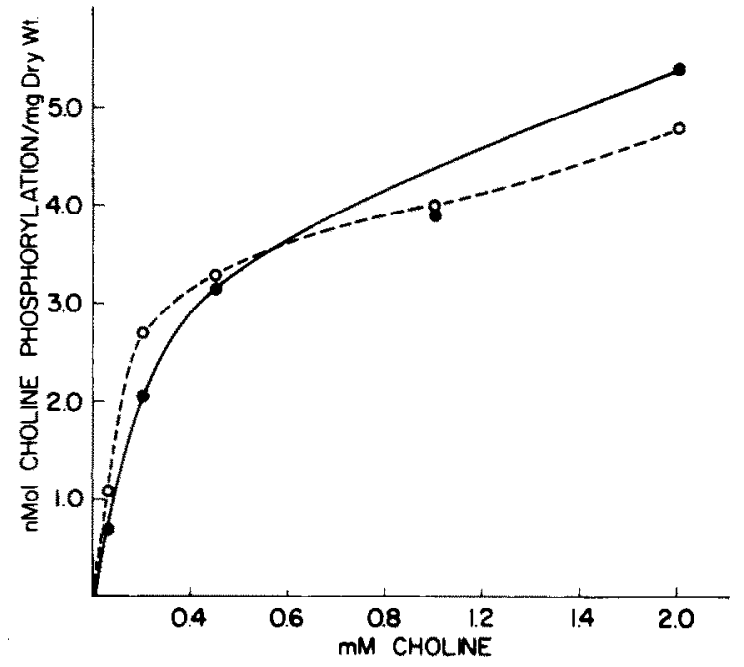

Fig. 4. The amount of choline phosphorylated during a 60 min incubation at varying concentrations of choline. The values were calculated as described in Fig. 3. •, slices from fetuses immediately after delivery; $o$, slices from fetuses that survived $3 \mathrm{~h}$.

into phosphorylcholine also occurred following $3 \mathrm{~h}$ of survival, similar to the results at 20 days gestation.

The determination of the changes in the specific activity of phosphorylcholine with increasing incubation time indicated that the decreased total incorporation of $\left[\right.$ methyl $\left.{ }^{14} \mathrm{C}\right]$ choline into phosphorylcholine in slices from 3 -h-surviving fetuses was associated with an increased specific activity of phosphorylcholine (Fig. 5). This inverse relationship suggested that a significant decrease in the concentration of phosphorylcholine occurred during the $3 \mathrm{~h}$ of survival, which indeed was the case. The concentration of phosphorylcholine decreased about $60 \%$ after $3 \mathrm{~h}$ of survival at both 20 and 21 days gestation $(8.0 \pm 1.7$ $(n=11)$ to $3.1 \pm 1.0(n=12)$ and $4.6 \pm 1.2(n=9)$ to $1.8 \pm 0.7(n=9) \mathrm{nmol} / \mathrm{mg}$ dry weight, respectively). Furthermore, the concentration of phosphorylcholine also decreased in utero from $8.0 \pm 1.7$ at 20 days to $4.6 \pm 1.2$ at 21 days gestation. This observation correlates well with the observation that $\left[\right.$ methyl $\left.{ }^{14} \mathrm{C}\right]$ choline incorporation into phosphatidylcholine also increases in utero between 20 and 21 days gestation. The concentration of phosphorylcholine in the tissue slices was the same at all incubation times, indicating that phosphorylcholine was not lost into the incubation medium to any significant extent during the incubation. 


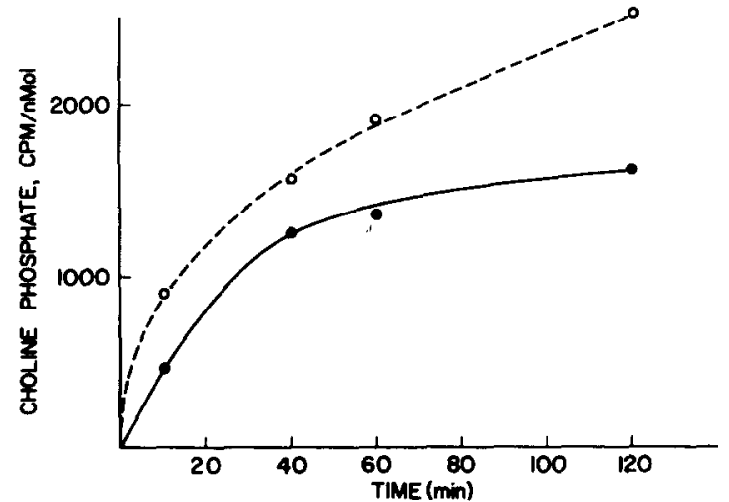

Fig. 5. Changes in the specific activity of phosphorylcholine in lung slices from 20-day gestation fetuses. Each point is the average of duplicate incubations. $\bullet$, slices from fetuses immediately after delivery; $\circ$, slices from fetuses that survived $3 \mathrm{~h}$.

\section{Enzyme activities}

The apparent changes in choline metabolism that occur after premature birth may be caused by changes in the activities of the enzymes in the pathway for de novo synthesis of phosphatidylcholine. We measured the activities of the enzymes choline kinase, cytidylyltransferase, cholinephosphotransferase, and phosphatidate phosphohydrolase, using assay conditions that produce maximal catalytic activities in vitro. The activity of choline kinase and cytidylyltransferase in the $100000 \times g$ supernatant fraction, and phosphatidate phosphohydrolase and choline- phosphotransferase in the total particulate fraction, did not change significantly during the $3 \mathrm{~h}$ period following premature birth at 20,21 and 22 days gestation (Table I). The activities of cytidylyltransferase, cholinephosphotransferase and phosphatidate phosphohydrolase had a slight tendency to increase after $3 \mathrm{~h}$ survival, but the increases were not statistically significant. We also measured the activity of cytidylyltransferase in the supernatant fraction in the absence of added lipid activator (phosphatidylgly. cerol). This 'lipid-independent' enzyme activity also did not change significantly following premature birth.

We previously demonstrated that cytidylyltransferase activity in the $100000 \times g \times 60 \mathrm{~min}$ supernatant can occur in a high molecular weight form ( $\mathrm{H}$ form) or a low molecular weight form ( $\mathrm{L}$ form) $[6,10]$. Therefore, we compared the size distribution of cytidylyltransferase activity in fetal lung at birth and after $3 \mathrm{~h}$ survival (Table I). During the last 3 days of gestation in utero, the enzyme activity exists predominantly in the $\mathrm{L}$ form. At $3 \mathrm{~h}$ after birth at 20 days gestation there was no apparent change in the size distribution of the enzyme activity in the $100000 \times g$ supernatant. However, after $3 \mathrm{~h}$ of survival following birth at 21 and 22 days gestation, the size distribution changes from predominantly $L$ form to more than $60 \% \mathrm{H}$ form, a pattern similar to that found in adult lung ( $73 \pm 17 \% \mathrm{H}$ form).

The cytidylyltransferase activities reported in

TABLE I

ENZYME ACTIVITIES AT PREMATURE BIRTH AND AFTER 3 h OF SURVIVAL

Activities are presented as $\mathrm{nmol} / \mathrm{min}$ per $100 \mathrm{mg}$ dry weight $\pm S$.E., with the number of separate experiments in parenthesis.

Enzyme

Activity

20 Days gestation

Birth $+3 \mathrm{~h}$

Cholinephosphotransferase Phosphatidase phosphohydrolase

Choline kinase

Cytidylyltransferase $\% \mathrm{H}$ form
21 Days gestation

Birth $+3 h$

$16.6 \pm 5(8)$

$18.7 \pm 3(8)$

$94 \pm 21(8)$

$78 \pm 9(4)$

$80 \pm 2(5)$

$73 \pm 32$
22 Days gestation

Birth $+3 h$

$26 \pm 9(10)$

$128 \pm 24(7) \quad 118 \pm 18(10)$

$96 \quad 81$

$71 \pm 5(3) \quad 92 \pm 7(3)$ 
Table I reflect the activity in the $100000 \times g$ supernatant fraction. Although, the largest amount of activity is recovered in this cytosol fraction, activity is also present in the microsomal fraction [10]. Preliminary experiments with both fetal and adult lung indicated that greater than $90 \%$ of the activity in homogenates was recovered in a $20000 \times g \times 30 \mathrm{~min}$ supernatant. Further centrifugation of this supernatant at $250000 \times g$ for $60 \mathrm{~min}$ resulted in a maximal sedimentation of membrane material. A com. parison of activities in the $250000 \times g$ microsome and supernatant fractions indicated that the activity recovered in the microsomes increased significantly from birth to $3 \mathrm{~h}$ after birth (Table II). At 20 days gestation the activity in microsomes increased about 2 -fold whereas the amount of activity in the supernatant fraction decreased. This result suggests that cytidylyltransferase which was 'soluble' in the lung immediately after delivery may have become attached to membranes during the first $3 \mathrm{~h}$ of survival. An increase in the activity in microsomes also occurred at 21 and 22 days gestation but to a somewhat lesser extent and with no apparent decrease in the activity in the cytosol. The increase in activity in the micro- some fraction apparently was dependent upon birth and/or subsequent breathing of the animal, since this shift did not occur in utero in animals induced to delay delivery for $24 \mathrm{~h}$ beyond the normal gestation period.

A comparison of enzyme-specific activities (nmol/ min per mg protein) in the microsome and cytosol preparations revealed that the increased cytidylyltransferase activity found in the microsomal preparations of lung tissue following $3 \mathrm{~h}$ of survival was not due simply to changes in the dry weight content of the lung. Furthermore, the increased activity in the microsomal fraction was not due to increased recovery of microsomes since the specific activity of the enzyme in microsomes increased similar to the total activity.

\section{Discussion}

The developmental control of the synthesis of phosphatidylcholine and particularly the dipalmitoyl species of phosphatidylcholine has received intense experimental effort with the expectation that an understanding of these regulatory mechanisms will

TABLE II

\section{DISTRIBUTION OF CYTIDYLYLTRANSFERASE ACTIVITY BETWEEN MICROSOMES AND CYTOSOL}

The microsome and cytosol fractions were isolated as described in Materials and Methods. The data is reported as the average \pm S.E., with the number of litters in parenthesis. The results at 23 days were obtained with pregnant animals treated with 4 mg medroxyprogesterone to delay delivery. The medroxyprogesterone was injected subcutaneously at 21 and 22 days of gestation.

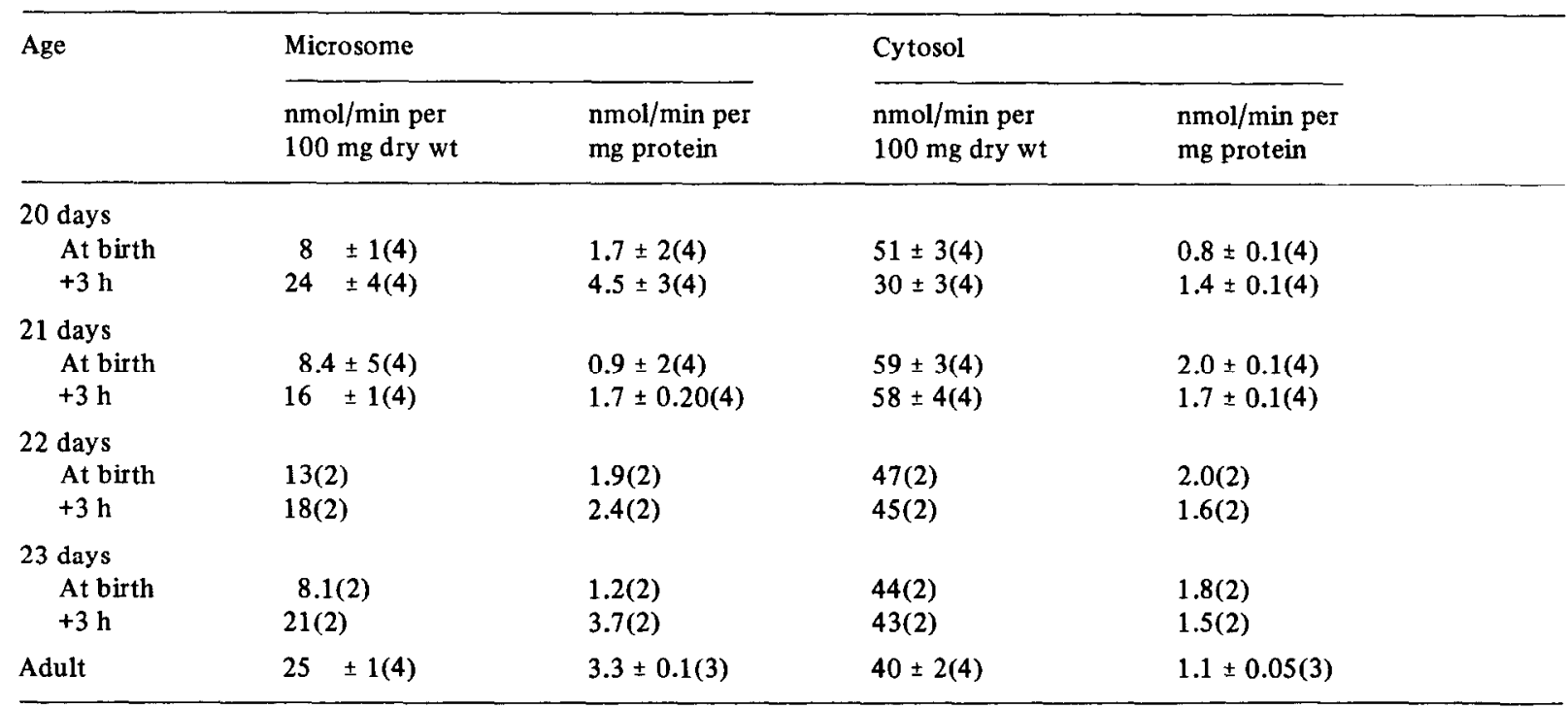


provide a conceptual basis for the treatment of neonatal respiratory distress syndrome. Considerable work has been directed towards defining the normal in utero developmental characteristics of the pathway and the potential hormonal influences on these developmental processes $[11,13,3]$. However, an additional consideration which is particularly relevant to the potential manifestation of respiratory distress, is an understanding of the 'adaptive' processes which enable the lung from a prematurely delivered fetus to function adequately even though the biosynthetic pathway for pulmonary surfactant formation is not yet fully developed. Apparently, the initial survival of fetuses following birth depends largely upon the secretion of surfactant from stored sources. The amount of phosphatidylcholine in the alveolar wash from both premature and term fetuses increases $8-10$ fold shortly after birth $[14,16]$. However, studies with rabbit fetuses clearly show that newly synthesized phosphatidylcholine appears in the alveolar wash only after $3 \mathrm{~h}$ of breathing [17]. The somewhat limited data available suggests that after the initial secretion of stored surfactant, the continued supply of alveolar surfactant depends upon new synthesis. Thus, even though the inital amount of stored surfactant phosphatidylcholine was lower in premature rabbit fetuses, the amount of phosphatidylcholine in the alveolar wash after $8 \mathrm{~h}$ of survival was the same with prematurely delivered and term fetuses [17]. Furthermore, in vivo data reported by Jobe et al. [18] indicated that $40 \mathrm{~min}$ of breathing results in an increased ability of lung to synthesize phosphatidylcholine from injected radioactive precursors. We previously reported [1] that lung slices from premature rat fetuses incorporate more radioactive choline into phosphatidylcholine after $1 \mathrm{~h}$ of breathing. These results suggest that shortly after respiration begins a more rapid synthesis of phosphatidylcholine also commences.

The present results substantiate the fact that the rate of $\left[\right.$ methyl $\left.l^{14} \mathrm{C}\right]$ choline incorporation into phosphatidylcholine is faster in lung slices from surviving fetuses. Furthermore, the experiments indicate that the increased incorporation of radioactive choline is not due to an increased rate of entry of choline into the pathway rather to a shift in the distribution of radioactive choline within the pathway. During the 3 $h$ of survival after premature delivery, the concentra- tion of phosphorylcholine in the lung decreases, resulting in a decreased dilution of the radioactive choline in the phosphorylcholine pool during the slice incubations and a subsequent increased specific activity of phosphorylcholine. This accounts for most of the increased amount of $\left[\right.$ methyl- $\left.{ }^{14} \mathrm{C}\right]$ choline incorporated into phosphatidylcholine. The decrease in phosphorylcholine concentration could have occurred as a result of either a decreased formation via choline kinase or an increased conversion by the cytidylyl. transferase reaction to CDPcholine. A decrease in the choline kinase reaction appears unlikely since the total amount of radioactive choline entering the pathway, as estimated from the summation of radioactivity in phosphorylcholine, CDPcholine and phosphatidylcholine did not change. Conceivably, the supply of choline to the lung during the $3 \mathrm{~h}$ of survival may have been low, which in turn may have produced a decrease in tissue choline content and a subsequent decrease in the amount of phosphorylcholine formed during that period. However, the fact that the amount of radioactive choline in the slice after different lengths of incubation and at different concentrations of radioactive choline in the medium was the same in newly delivered fetuses and in animals surviving $3 \mathrm{~h}$ argues against a significant change in the pool size of choline. Thus, an increase in the activity of the cytidylyltransferase-catalyzed formation of CDPcholine from phosphorylcholine over the $3 \mathrm{~h}$ period appears to be a more plausible explanation.

The rate of this step in the pathway, as calculated from the specific activity of the phosphorylcholine and the total amount of radioactivity incorporated into CDPcholine plus phosphatidylcholine, apparently is increased in lung slices from animals $3 \mathrm{~h}$ after delivery (Table III). This type of experiment, and the subsequent calculations, assumes that the phosphorylcholine isolated from the slices comes from a single pool which is uniformly available for conversion to CDPcholine. While these assumptions place limitations on the interpretations, the data is consistent with an increase in cytidylyltransferase as the primary cause for the decrease in concentration of phosphorylcholine.

Cytidylyltransferase activity, measured in vitro under conditions designed to measure the maximal enzyme capacity, did not change significantly following premature birth, nor did the activities of the other 


\section{TABLE III}

ESTIMATION OF THE CYTIDYLYLTRANSFERASE REACTION IN LUNG SLICES FROM FETUSES AND SURVIVING NEWBORNS AT 20 DAYS GESTATION

The rate of the reaction was estimated in slices over the 20 min period between $20 \mathrm{~min}$ of incubation and $40 \mathrm{~min}$ of incubation. The increase in radioactivity incorporated into the sum of CDPcholine and phosphatidylcholine during the $20 \mathrm{~min}$ period was divided by the average of the specific activities of phosphorylcholine at 20 and $40 \mathrm{~min}$ of incubation. Three separate and independent experiments were performed, each involved the combined litters from three pregnant animals.

\begin{tabular}{lccl}
\hline Experiment & \multicolumn{2}{l}{$\begin{array}{l}\text { Reaction rate (nmol/min per } \\
100 \mathrm{mg} \text { dry wt) }\end{array}$} \\
\cline { 2 - 4 } & At birth & $3 \mathrm{~h}$ after birth & $\%$ increase \\
\hline I & 9.4 & 13.2 & 40 \\
II & 15.9 & 18.8 & 18 \\
III & 18.9 & 23.6 & 25
\end{tabular}

enzymes in the pathway. However, the subcellular distribution of cytidylyltransferase was significantly different in the 3 -h newborns. The activity associated with membrane material isolated in the microsomal fraction increased. These results are consistent with the postulate that the active form of cytidylyltransferase in the cell is a membrane-bound form of the enzyme, and that the regulation of the activity of cytidylyltransferase and in turn the control of the pathway for phosphatidylcholine synthesis involves binding of soluble, inactive cytidylyltransferase to membranes, resulting in activation of the enzyme. Thus, following premature birth some process, as yet unknown, occurs which results in increased attachment of cytidylyltransferase to sites on cellular membranes. This leads to a rapid increase in the activity of cytidylyltransferase. The increased cytidylyltransferase activity depletes the concentration of phos. phorylcholine while increasing the synthesis of phosphatidylcholine. The increase in amount of $\mathrm{H}$ form of the enzyme that occurs following premature birth at 21 days gestation and at term may also reflect an attachment of cytidylyltransferase to membranes since the physical characteristics of this form of the enzyme suggest that it consists of small membrane fragments [6]. Perhaps as lung development progresses a more extensive response of the cytidylyltransferase system involves both an increased activity of membrane form recovered in the microsome fraction and a conversion within the cytosol of the $L$ form of the enzyme to the $\mathrm{H}$ form of the enzyme. In either case, the change from a primarily soluble form to a more complex form of cytidylyltransferase required active breathing of the animals since no change occurred in utero at 21,22 or 23 day gestation (Tables I and II).

Although the relationships and relative importance of the $\mathrm{L}$ form, $\mathrm{H}$ form and microsome form of cytidylyltransferase in the developmental control of phosphatidylcholine synthesis remains unclear, evidence has accumulated which suggests that cytidyl. yltransferase activity is controlled by enzymemodulator interactions rather than by changes in the amount of enzyme. Choy et al. [19] clearly showed that cytidylyltransferase activity increased in HeLa cells after infection with poliovirus. The total activity of cytidylyltransferase, measured under optimal conditions in vitro, did not increase, leading them to conclude that the amount of enzyme does not influence the rate of the cytidylyltransferase reaction but rather that the enzyme activity is controlled by changes in the concentration of substrate or products or by a change in an unknown effector. They subsequently presented data indicating that in this case the concentration of the substrate CTP was probably regulating the reaction rate $[20]$. Equally convincing results have been obtained in studies on choline deficiency in the rat. Choline deficiency leads to a decrease in cytidylyltransferase activity, yet the amount of enzyme present, as determined by immunotitration, is unchanged $[21,22]$. Studies of cytidylyltransferase activity during lung development $[10]$ and after hormonal treatment $[23,24]$ also suggest that the activity of cytidylyltransferase is increased by increasing the proportion of active enzyme rather than by increasing the amount of enzyme protein. Thus, a wide variety of experiments designed to study the regulation of the pathway for the de novo synthesis of phosphatidylcholine in lung and liver in vivo indicated that the cytidylyltransferase reaction is a significant site for the control of the rate of the pathway. Studies of the enzyme in vitro revealed a wide variety of regulatory properties which appear to provide several efficient ways to modulate the enzyme activity and to coordinate the activity with other metabolic processes. 


\section{Acknowledgements}

This work was supported by the Veterans Administration and by grant HD 02871 from the National Institute of Child Health and Human Development.

\section{References}

1 Weinhold, P.A., Quade, M.M., Brozowski, T.B. and Feldman, D.A. (1980 Biochim. Biophys. Acta 617, 76-84

2 Gilden, C.A., Sevanian, D.F., Tierney, D.F., Kaplan, S.A. and Barrett, C.T. (1977) Pediatr. Res. 11, 845

3 Ballard, P.L. (1977) Fed. Proc. 36, 2660-2665

4 Weinhold, P.A. and Rethy, V.B. (1974) Biochemistry, 13, 5135-5141

5 Ravinu thala, H.R., Miller, J.C. and Weinhold, P.A. (1978) Biochim. Biophys. Acta 530, 347-356

6 Feldman, D.A., Kovac, C.R., Dranginis, P.L. and Weinhold, P.A. (1978) J. Biol. Chem. 253, 4980-4986

7 Choy, P.C., Whitebread, F.W. and Vance, D.E. (1978) Can. J. Biochem. 56, 831-835

8 Burton, K. (1956) Biochem. J. 62, 315-321

9 Lowry, O.H., Rosebrough, N.J. Farr, A.L. and Randall, R.J. (1951) J. Biol. Chem. 193, 265-275

10 Stern, W., Kovac, C. and Weinhold, P.A. (1976) Biochim. Biophys. Acta 441, 280-293
11 Rooney, S.A. (1979) Trends Biochem. Sci. 4, 189-191

12 Farrell, P.M. and Morgan, T.E. (1977) in Development of the Lung (Hodson, W.A., ed.), pp. 309-347, Marcel Dekker Inc., New York

13 Taeusch, H.W. and Avery, M.E. (1977) in Development of the Lung, W.A. (Hodson, W.A., ed.), pp. 399-418, Marcel Dekker Inc., New York

14 Gluck, L., Sribney, M. and Kulovich, M.V. (1967) Pediat. Res. 1, 247-265

15 Kikkawa, Y., Motoyama, E.K. and Gluck, L. (1968) Am. J. Pathol. 52, 177-209

16 Rooney, S.A., Gobran, L.I. and Wai-Lee, T.S. (1977) 3. Clin. Invest. 60, 754-759

17 Jobe, A. and Gluck, L. (1979) Pediat. Res. 13, 635-640

18 Jobe, A., Manning, F. and Gluck, L. (1978) Am. J. Obstet. Gynecol. 132, 53-58

19 Choy, P.C., Paddon, H.B. and Vance, D.E. (1980) J. Biol. Chem. 255, 1070-1073

20 Vance, D.E., Trip, E.M. and Paddon, H.B. (1980) J. Biol. Chem. 255, 1064-1069

21 Schneider, W.J. and Vance, D.E. (1978) Eur. J. Biochem. $85,181-187$

22 Choy, P.C., Schneider, W.J. and Vance, D.E. (1978) Eur. J. Biochem. 85, 189-193

23 Khosla, S.S., Gobran, L.I. and Rooney, S.A. (1980) Biochim. Biophys. Acta $617,282-290$

24 Rooney, S.A., Gobran, L.I., Marino, P.A., Maniscalco, W.M. and Gross, I. (1979) Biochim. Biophys. Acta 572, $64-76$ 